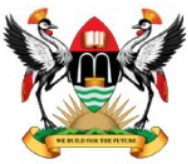

East African School of Higher Education Studies \& Development

\title{
Intellectual Curiosity or Deception? An Investigation into the Practice of Teaching outside Area of Expertise in Uganda
}

\author{
Maria Kaguhangire Barifaijo ${ }^{1,}$, Proscovia Namubiru Ssentamu ${ }^{1}$ \\ ${ }^{1}$ Uganda Management Institute [* Corresponding author: mbkaguhangire@umi.ac.ug]
}

\begin{abstract}
Teaching outside one's area of expertise is increasingly common in higher education institutions (HEIs). Yet institutions and scholars are treating the subject as a taboo. Debate on the subject has been kept hush-hush-citing potential jeopardy to the institutions' image. In this paper, the authors explore the reasons for the trend. The authors adopted Carl Rogers' Theory to answer four questions: 1) What drives academicians to teach outside their area of primary expertise? 2) What are the implications of teaching outside one's area of expertise? 3) What is the performance of those teaching outside their expertise? 4) What strategies are in place to regulate the practice? Data was collected from two HEIs in Uganda. This was done using interviews, students' evaluations and teaching time-tables. Staff job descriptions and profiles were also analysed. It was concluded that the practice is not affecting quality. Regardless, the paper urges HEIs to be judicious in allowing the practice.
\end{abstract}

Keywords: Teaching and learning; Quality assurance; Professionalism.

\section{$1 \quad$ Introduction}

This paper assesses the implications of teaching outside one's area of expertise. It sought to establish what drives individuals to want to teach courses in which they have no expertise. The researchers were intrigued by claims that some academics taught outside their areas of expertise yet institutions have rigorously laboured to attract and hire staff to teach on specific programmes because of their expertise. We note that HEIs are no longer enclaves of small groups of privileged students that dominated universities in the past. We are now dealing with mass institutions where lecturers or facilitators are engrossed in the Aristotelian approach to teaching (Cranton, 2002). Although the authors' major objective was to explore the expertise of those teaching in higher education 
institutions and their engagement, they bring out diversity challenges such as background, quality and age of students; size of classes, social and educational background; and psychological factors that may require peculiar skills. In this connection, Huston (2009) has argued that while there are many individuals who engage in teaching, there will always be those remembered for their great teaching and others will be forgotten or remembered for being muddled. So, whether you are remembered for good works or muddled work, it is important to understand why this happens.

We shall systematically highlight how, when and why such practice takes place by attempting to respond to a number of puzzling questions: Do people teach what they did not study out of intellectual curiosity or deception? The second puzzle that remained unresolved in literature was: What really matters content expertise or masterly of teaching methods? Perhaps this is what sometimes confuses leaders in HEIs while hiring and engaging academicians. So then, is it the qualification (e.g., Masters, PhD)? Is it the research experience (number of research reports, publications and books written)? Is it the pedagogical and andragogical training (evidence or certificates attained)? Is it the area of expertise? Or does a combination of all the above matter? These are heavy-laden questions that call for immediate answers if institutions are to uphold quality, integrity and excellence. The third puzzle that may sound obvious is intended to mitigate potential questions from the readers of this article: Does the area of expertise matter if one can do a good job at what they do? But in this regard there is also a pertinent question: Who determines a good job in teaching? It has been observed that more often than not, that those who do a bad job at teaching get away with it because there is not much accountability other than students' evaluations; which many times are subjective - depending on the personality of the facilitator and the motivation of the learners (Huston, 2009).

\subsection{Theoretical Underpinning}

Carl Rogers and others have developed the theory of facilitative learning. The basic premise of this theory is that learning will occur by the educator acting as a facilitator, that is by establishing an atmosphere in which learners feel comfortable to consider new ideas and are not threatened by external factors (Laird, 1985). Other characteristics of this theory include; a belief that human beings have a natural eagerness to learn and that there is some resistance to and unpleasant consequences of giving up what is currently held to be true. The most significant learning involves changing the concept of oneself that requires self-learning, creativity and high motivation. Facilitative teachers are less protective of their constructs and beliefs than other teachers; more able to listen to learners, especially to their feelings; inclined to pay as much attention to 
their relationship with learners as to the content of the course; apt to accept feedback, both positive and negative and to use it as constructive insight for themselves and their behaviour. Hence, it is argued that only when one is knowledgeable, prepared and confident, that he or she will be quite receptive of any feedback from the students. Therefore, one could have content expertise without confidence to impart knowledge. Conversely, one may lack content expertise but have superior delivery skills that make him or her shine beyond expectation. The worst scenario, however, could be where one lacks both the content (expertise) and the skill to deliver; which might be disastrous not only for the individual facilitator, but to the students and to the institution as a whole.

\subsection{Conceptual Underpinning}

This section first introduces the two major terms that guide this discussion, and these are: content expert and content novice. A 'content expert' is someone who has extensive specialized knowledge about a given topic. On the other hand, a 'content novice' is someone who has little or no specialized knowledge of a given topic. Even a seasoned instructor could be a content novice in certain classes. Hence, the concern of this discussion is about a content novice. Huston (2009) found that content novices prepared well in time before they stepped in class, and possibly this was why most got away with it and instead truly earn students' respect. This might sound like a no-brainer, but Huston (2009) found that when people teach outside their expertise, they are pressed for time and they read things their students have not read. After all, they want to bring new ideas to class. Does this sound logical? Possibly yes. Those who take the angle of intellectual curiosity, for example, will definitely invest hours and hours researching for the right materials on the area they want to get acquainted with; one, for self-learning, and two, to impress students they will interact with in the learning environment. However, Huston (2009) cautions that this is a dangerous strategy, especially if the learners are widely read and might be in superior position to judge the content being taught. On the contrary, lecturers who are deceptive for various selfish gain, will certainly lose credibility with their students, especially when they exhibit unfamiliarity with what they attempt to teach.

The most fundamental fact, according to Huston (2009), is that although university lecturers have a duty to educate students, they are not teachers, no matter how great the teaching focus of our institutions is. The job advertisements are precise and usually indicate specific skills required in the 'person specifications' section for a particular discipline. Expertise required in one discipline will be different from another discipline. There are areas of specialization required for each discipline, in addition to the various levels 
(e.g., a Master's degree, a doctorate or a professional level of attainment). However, a qualification in university teaching may not be required (Brookfield, 2005) unlike at the lower levels of education. This may serve to explain why a university lecturer teaches without prior classroom training and gets away with it.

\subsection{Context}

Essentially, there has been unprecedented demand for higher education in Uganda, much like in other parts of the world (Kasozi, 2006), in the last two decades. This trend has led to increased student enrolment, and consequently, the government continues to grapple with the challenge of equity and access, amidst diminishing national budgetary allocations for public universities. In order to respond to these challenges, institutions have had to develop more marketable academic programmes, some of which lack experts, while others are oversubscribed, consequently undesirably affecting the lecturer-student ratios and student-space/computer ratios, among others. Further, performance-related pay in these institutions has forced many academicians to teach what they can lay their hands on in order to earn workload, regardless of whether they have expertise or not. This development has not only negatively impacted on the quality of teaching but also the quality of graduates (Kasozi, 2006).

Whereas we cannot decry the availability of superior experienced teaching staff in Ugandan universities, serious challenges have been registered regarding equitable and competitive salaries for staff in these universities (Barifaijo et al, 2015). Further, internal competition has led these universities to adopt the Results-Oriented-Management (ROM) approach that gave birth to the workload policy, which aimed at achieving 'performance-related pay' in many of Uganda's HEIs. For example, one must teach specified minimum hours; depending on one's status (principal, dean or head) or rank (professor, associate professor, senior lecturer, lecturer or teaching assistant), regardless of other engagements such as research, consultancy and community-related activities. Conversely, competition for qualified staff has loomed high in these institutions, which has left public institutions especially, considerably depleted of highly trained staff as a result of uncompetitive compensation (Barifaijo et al., 2015). Consequently, institutionalization of performance-related pay policies and practices were seen to limit the number of qualified staff amidst the increased demand for 'value for money' by various stakeholders; and demand for quality teaching and learning processes that has become a challenging one. Little wonder, therefore, that some staff have ended up teaching courses outside their expertise, thereby exacerbating the quality of delivery and consequently the quality of graduates from HEIs in Uganda. 


\section{$2 \quad$ Methodology}

Makerere University and Uganda Management Institute were sampled from the five public higher education institutions. This choice was a deliberate effort to establish the said problems in highly differentiated institution like Uganda Management Institute, that deals purely with graduate programmes and Makerere University with a continuum of programmes right from undergraduate to doctoral and research programmes. Kothari (2004) supports this choice because it brings out clearly the management-related challenges. Academic staff in Makerere purposively selected, specifically in trying to compare those teaching undergraduate courses and graduate courses. At the same time, participants at UMI were randomly selected considering that all programmes at were a higher level (postgraduate, Master's and $\mathrm{PhD}$ ). At the same time, Makerere University being largely dominated by undergraduate programmes gave us a clearer picture on which facilitators teach which level and why. The study used a qualitative approach augmented by the ethnographic method as recommended by Kothari (2004). Data was collected through interviews with lecturers and students from the two institutions. Documents such as students' evaluations, time-tables and staff job descriptions and profiles were reviewed, analysed and interpreted and personal files for staff were accessed and analysed. Participant-as-observer was used to complement other data sources.

\section{$3 \quad$ Findings and Discussion}

Teaching outside one's expertise has existed since the $18^{\text {th }}$ century as propounded in Jacotot's philosophy. But those were days when there was no higher education philosophy and terms such as quality and specialization had not emerged. Although this discussion slightly departs from Jacotot's thinking, in terms of the current beliefs, it borrows much that explains the current practice or why people do what they do, and why they excel in doing what they are not supposed to be doing.

We must say that the findings were extremely conflicting but interesting; and the results were quite mixed but intriguing. The first impression we got, which is actually supported in the existing literature was that what compels people to teach on the edge of their expertise was to try out something new and of importance - possibly the most interesting and positive finding. Secondly, other reasons were to enable individuals gain insight and become relevant; and thirdly, and probably most controversial, was individuals' inherent competition to "be equal to" or "be better than" their colleagues. Perhaps what was found to 
be the root cause of teaching outside one's expertise, but being downplayed and most times swept under the carpet by institutions, was the issue of unrealistic policies of what comprised workload. We actually found that what was considered "workload" was "teaching load" - especially given the diverse roles and mandates of these institutions.

\subsection{Why do Individuals Teach outside their Expertise?}

There was no consensus about why individuals teach what they did not study. There was also no serious contestation on the matter. There is a whole continuum of reasons including: mere interest; curiosity; to prove one's worth; to remain relevant; to respond to institutional pressures; to help out friends; to obey the supervisor's rules, etc. The findings and discussion in this article were majorly guided by the educational theory and practice of Joseph Jacotot who advanced possibilities of excelling in teaching a subject one did not even know in the first place. For Jacotot, teaching is not really a matter of expertise, but of determination. It is not about transmitting knowledge to the student, but holding students accountable to the material that they are working on. We endeavoured to explore whether what happened in these institutions could be explained by Jacotot's philosophy of the $18^{\text {th }}$ century. We found that the majority of the academic staff had actually "tried something new" or taught the whole curriculum for that matter, covering a whole range of topics, and this varied from individual to individual, and from institution to institution.

Although one of the institutions encouraged this practice, citing cases of mediocrity on the part of those who remained in their comfort zones, others did not believe in one individual being good in everything.

A key informant from one of the institutions defended teaching outside expertise thus:

"We actually encourage staff to diversify if they have to cope with the changing demands of society, especially our learners, the market nationally and internationally. If we limited these young brains to only what they studied, we shall be doing a disservice to them and denying them opportunities ahead of them. What matters in my view, is how do we exploit full potential of these young people? How do we get the best out of them? How do we encourage them to move forward? Let us plan for them through training and development in order to institute a succession plan for current and future success.”

Although Kasozi (2006) cautions institutions to stick to what was learned in universities in order to avoid curriculum drift, the above excerpt counteracts Kasozi's reasoning. According to Kasozi (2006) still, staff should be limited on the number of courses one can be responsible for in order to avoid work 
overload. Although this last aspect sounds logical, we doubt that work overload is contributed by different courses one teaches.

Some of the most interesting but rare findings on why individuals teach outside their areas of specialization were: making positive interactions with other professionals in other departments; broadening their curriculum vitae; and remaining relevant and competitive, both nationally and internationally. In support of this finding, Nilson 2007) and McKeachie and Marilla (2006) found that many firms wanted consultants who are multidisciplinary to take on numerous tasks and solve problems with one 'brain' - one head - and one location. This was supported by many respondents who argued that being multi-disciplinary increases one's opportunities and leverages one to higher advantages and sometimes expands one's repertoire that makes one stand out to potential superior consultancies. This argument was supported by Hsien-Hui \& Emily (2013) (2013) who explain how the need to respond to the global economic, environmental and social changes, has increased momentum to create awareness about diverse thinking among all professions by teaching interdisciplinary courses to heighten the thinking of students in higher education. We argue that this cannot be done unless the teachers themselves have diversified in their approach.

Still on the question of why people teach outside their areas of expertise, below as some of the responses:

"..my enthusiasm was borne out of frustrations arising from workload deficit...after teaching for six (6) months, I realized that I have a deficit of 120 hours and I had to think very fast how I was to reverse this record...I started by moving around different departments, requesting for teaching slots as well as materials... at the beginning it was indeed a challenge because those notes (slides) were just summaries...for some time I was not comfortable with questions from students because I wasn't sure of the answers. I had to come up with a better strategy, for example going to the library, access materials on the internet and also consult my superiors...now I consider myself an expert."

Another one had this to say:

"..my head of department was traveling and asked me to step in for him...because I was not very comfortable, I consulted on a number of areas which included; content, scope, instructional methodology, teaching materials and how best I could engage students maximally...my wish was to keep the students vibrant, motivated and alert...the first time I taught what I had never learnt... I believe I made an impact and that's when I realized that I could actually do a better job not only in my area, but elsewhere...I was very anxious and wanted to know how I was evaluated at the end of the module. I actually found that I had exceeded my own expectation." 
Although this was not intended curiosity, the task was approached with zeal, willingness and enthusiasm. This finding confirms Huston's (2009) finding, that although scholars argue that one can be comfortable where they are content experts, an instructor's level of prior teaching experience does not necessarily translate into comfort levels. However, she cautions those who want to venture to do a truly good job to do adequate preparation and ensure engagement with students.

\subsection{Implications of Teaching outside Area of Expertise}

Surprisingly, although it was premised that those teaching outside their expertise would affect academic standards of these institutions, we found that some of the personalities considered to possess less experience and content knowledge in these institutions actually had the best evaluations by students. This might sound a "no-brainer", but consistently (i.e. from 2012 to 2014), these personalities considered to possess less experience, scored $85-100 \%$ in all the classes. The same personalities were found to have exceeded institutions' expectations in terms of teaching load. The same personalities have not only met their targets but have been rewarded financially, through performance-related pay for going over and above their set targets.

This finding was also augmented by Bain (2004) especially with the advent of the internet which provides many sources of information. Bain found that the more one reads, the more information one acquires, although, he was quite sceptical about ability and competence in delivery. For example, research by Barifaijo et al. (2015) found that the aspect of workload computation had largely led many academic staff into teaching outside their areas of expertise/ specialisation. This clearly was deception driven by institutional requirements.

Explaining the issue of workload, one head of department gave the example of the modular system where if a lecturer missed his or her slot of teaching, the students would miss the topic. The issue was structural because of the nature of the programmes. The problem was increased by clients who demanded "value for money". He, however, that the institution had pronounced itself on those who taught outside their expertise because "we do not encourage deception".

Although, some empirical evidence showed that some academicians had performed better in disciplines they never studied in college than the subject specialists, Smith and Mistry (2009) argued that determination of whether one performed well depended on numerous factors. For example, although some of the facilitators perceived to be deceptive had the best evaluations by students, Huston (2009) cautions against relying on such to determine quality. Therefore, we are inclined to agree with Huston, especially after interacting with the students on their reasons for evaluating lecturers positively or negatively. 
Students revealed that most did not bother to judge the quality and comprehensiveness of content from an analytical perspective. In one of the responses, a student remarked:

"Quality and comprehensiveness? Who cares? Seriously that is not for me to judge! The institution should take care of that...I pay to be taught and I expect to find knowledgeable teachers at this institution... or else I would not be here...I am sure you do not require us to challenge our teachers... You expect us to have time to read after here...but, where is the time?...we believe that the notes from class suffice.."

On a question about decisions made to evaluate their teachers/facilitators, the students argued that the fact that the evaluations coincided with the end of module tests meant that students were overwhelmed by,

"... anxiety, uncertainty, rage, panic and most times we do not think straight on that day...it all depends on what comes first.....if the teacher has been generous, humorous, kind and not taking us beyond the recommended time, students will always evaluate them highly...and those that have been harsh and mean with marks... students will definitely evaluate them poorly even if is dissatisfaction with the previous module -no matter their current performance, first impression matters."

This subjectivity in students' evaluation was also affirmed by Race (2007), who on the contrary, found that what we believe to be important for the students may actually not be what they value. He found that whereas many prepare lots of notes for the students, to some, at evaluation, their decisions are determined by different parameters altogether. Therefore, researchers (e.g., Brookfield, 2005; Svinicki, 1999) found that students value flexible study time and group discussions which give them a chance to assess their ability and potential. On the other hand, Demeroutiet al (2001) found that, surprisingly, most university students did not know their role and this was blamed on teacher-centred method of teaching. The researchers encouraged participatory teaching so the learning could make more sense. Indeed, Race (2007) found that participation was higher when supported by use of visual aid, role plays, demonstration, and video clips which make the structure of the knowledge clearer. We also found that students learn with greater understanding when they share ideas through conversation, debate, and negotiation.

However, content novices were found to use mostly the lecture method which was limiting in nature. Although we attributed this limitation to content novices, some content experts found it difficult to organize a class activity that can translate into learning. He asserted that being a content expert may actually not make you a better teacher. He explained how to be a better teacher one must possess both content and methodological expertise - which attributes are 
rarely found in many teachers. In fact, we observed specific cases where lecturers really struggled, especially at the beginning of a module, where the facilitator lacked the ability to introduce the content appropriately, failed to define concepts, was unable to link the subject to any model or theories, no visible discipline-related frameworks and principles.

During our observation, most content novices did not have references and believed reading notes to students. However, we also found that it was not only the content novices who encountered this dilemma, but some of the content experts sometimes failed to involve the learners. However, it is observed that although both may experience this situation, those with expertise will always find a way to rectify this situation. Effective teaching may not be a matter of what one studied at college and may not to a large extent affect one's delivery methods, it is important that one gets more acquainted with the materials - at least to sound smarter than the students.

Some lecturers taught outside their areas of expertise because they had been asked to, especially when they were new and the head of department assigned them teaching slots. Some respondents explained how some opportunities come to those who can do something unusual or peculiar. For example, in an interview with one of the respondents the following was noted:

"...a certain company was looking for a consultant in "process reengineering" and there was some good money...I had to accept, revise my curriculum vitae and I thereafter read about it....I must say, I understood better than when my professor taught me in first year at university.... I must say I excelled in doing the work and thereafter I started teaching it. I taught it perfectly well and was highly evaluated by my students..."

This means therefore that some courses are cornerstones and actually some are an amalgam of the most compelling ideas and practices from various fields (McKeachie \& Marilla, 2006). On the other hand, new areas generate new areas of research that can actually expand the knowledge base in order to develop one's teaching competence, as another lecturer claimed:

"...with all these materials around, how can I fail to teach any subject related to my area? Only mathematical subjects such as quantitative methods, financial management, etc...otherwise it is possible to teach anything..."

We found that most lecturers who taught outside their comfort zone were enjoying what they did. Therefore, taking the first step of a new subject-matter, teach from a non-expert standpoint, and become creative, select what to read and give assignments to students can sometimes be exciting (Gappa, Austin \& Trice, 2007). They, however, caution that although this new experience was exciting, it can sometimes cause stress and anxiety, because, it is a burden to 
prepare a new course in an area in which one has not significantly researched as observed by a respondent:

"Actually, I now know that I can do better where I did not originally have expertise. However, it is real hard work because you need to first and foremost understand the conceptualization...I believe that's what is important...reading to understand so we can make students understand..."

Another respondent said:

"I am just interested in the subject...I never got a chance to study it but when I began reading on my own, I picked interest and when I offered to teach it, I realized I was doing a good job...possibly better than on those courses where I had more experience.?

Visibly, one could read the motivation, zeal and so much enthusiasm which we interpreted to be intellectual curiosity. Huston (2009) found that although such people are genuine, they require mentoring and training to perfect their work. Research has found that actually, some content novices have brought excitement and motivation to students, because, many times, this interaction between what students know, the new information they encounter, and the activities they engage in as they learn, brings realistic expectations (Orrell, 2011).

\subsection{Performance of People Teaching outside their Expertise}

Contrary to the findings of Gappa, Austin and Trice (2007), Huston (2009) reiterate how occasionally non-experts do bring strengths to the classroom if they have the motivation and enthusiasm. We actually found that these lecturers expend extra time in preparation and, many a time, have realistic expectations of their students. Huston (2009) argues that their conscience will compel them to focus on concrete explanations of problems and phenomena. Hence, this awareness will guide content novices to plan and manage their time, course content, and in the end are respected by the students (Nilson, 2007).

We found a number of students at graduate level who were motivated to learn and can construct their own understanding through work experience, interactions with content and also reflection. This finding collaborates with, for example Orrell (2011), Race (2007) and Mulryan-Kyne (2010) who found that superior content expertise brings out the best from the learners and provides them opportunities to connect with the lecturer's content in a variety of meaningful ways, especially through the usage of cooperative learning, interactive lectures, engaging assignments, hands-on field experiences, and other active learning strategies, that are often used by experienced lecturers. 
Students do not come to a lecturer's class as blank slates. They use what they already know about a topic to interpret new information.

When students cannot relate new material to what they already know, they tend to memorize-learning for the test-rather than developing real understanding of the content. Another superior method used by experienced or content experts, according to Svinicki (1999), is utilization of students' experiences, preconceptions, or misconceptions by using pre-tests, background knowledge probes, and written or oral activities designed to reveal students' thinking about the topic. This is usually done at the beginning of a new course or module to level the ground. The lack of this approach especially due to lack of experience or content expertise has let many students to become passive learners as they are not often given the opportunity to express themselves or share their own views. This was reflected in the way students were not able to tell between authentic and façade in the content imparted.

Through our participant-observer technique, students' evaluations, and yearly performance appraisals, there were inconsistencies on what exactly constitutes content expertise and whether this expertise translates into superior teaching. For example, Donovan, Bransford and Pelegrino (1999) argued that although content expertise of the subject matter was the most important factor in delivering a quality education, they doubted whether professors with doctorates and a long list of publications in their field would be the best teachers and if they were superior in preparing the best graduates.

Unless teachers know how to engage their students in the lessons they have prepared, expertise in the subject matter counts for very little. Therefore, Lang (2008) explains clearly how teachers or lecturers alike can never possess uniform abilities. He argues that how there will always be a few teachers who are naturals and indeed good at whatever they touch on and there are those who, regardless of the training acquired, may never change. Teachers grow in selfconfidence as they experience success in delivery, just as they lose confidence in the face of repeated failure or if immediate feedback from the learners is not favourable (Brookfield, 1995).

Although education has always been awash with new ideas about learning and teaching, Huston (2009) believes that probably this was why everyone feels they can teach anything. Therefore, theories of learning, whether explicit or tacit, informed by study or intuition, well-considered or not, play a role in the choices lecturers make concerning their teaching (Donovan, Bransford \& Pelegrino, 1999).Therefore, we note, that the major trend in understanding how students learn has been a movement away from the behaviourist model to a cognitive view of learning.

Similarly, Ganster and Rosen (2013) caution managers of higher education institutions to be more conscious about educational quality assurance through talent identification and attraction, in order to achieve the best results. 
On the performance of those who teach outside their expertise, one official in charge of academic affairs had this to say:

"This is deception indeed, because we have very clear recruitment procedures where all key stakeholders are involved. For example departments identify gaps and a specific content expert cannot be found in the institution, we encourage them to recommend experts from sister institutions and we hire them on part-time basis (associate consultants). We strongly discourage this quandary and even demand for teaching time tables, to be published, first, for transparency and second, for ironing out such malpractices of people teaching what they are not supposed to teach. Actually we have summoned those suspected to engage in such malpractices.....we have adequate staffing in terms of numbers and specialization. If this practice is still continuing, then we need to double our vigilance through module leaders, course managers, head of departments and deans.

Concerns about quality of delivery aside, research output, and service to community were found to have suffered the same fate. The most alarming situation was where the teaching function has actually overshadowed other mandates of higher education institutions. Bain (2004), for example, cautions institutions on research output. $\mathrm{He}$ advises institutions to find ways of balancing the three mandates of teaching/training, research and service to community/consultancy.

\subsection{Strategies to Regulate Teaching outside Area of Expertise}

We must say that although we went out with an assumption that the practice of teaching outside one's expertise was a form of deception, some did not perceive it that way. Actually, some institutions perceived those who confine themselves to what they studied as mediocre. However, citing the legal provisions, for example the National Council for Higher Education (NCHE), Kasozi (2006), believes that this was a timely and purposive strategy to uphold the country's long-standing high standards of education. He also argues that for purposes of accountability and quality, every individual must belong to some discipline and be a professional in what they specialized in.

However, both institutions investigated were found to have very clear guidelines in place in terms of who they engage on programmes and why. For example, one of the institutions had very clear guidelines regarding who teaches what. One of the strategies was that of rigorous attraction and procurement of the right talent, training them, and deploying them in the right places. The second strategy was pedagogical training that is always organized for the new staff. The third strategy was that of target setting by individuals 
and identification individual gaps which the institution endeavours to close whenever opportunities and resources allow. The fourth strategy was that of tracer studies that are intended to strengthen quality in terms of skills development. The fifth strategy was the quality assurance unit's role in the collection of data, analysing it and disseminating it - regarding the quality of teaching, available and required resources and coordinating and following up of recommendations by students through their evaluations. The sixth strategy, and possibly the most central aspect for this discussion, is the requirement to publish teaching time-tables for the entire semester which must be accessed the officer responsible for programmes, the teaching and learning.

However, although institutions preach quality teaching and argue how it matters, not all actors in higher education consider it a priority, understand and recognize what constitutes quality teaching, or are willing and able to play a role in ensuring it takes place in their institutions. Consequently, while institutions play the key role in fostering quality teaching, national regulations rarely require or prompt academics to be trained in pedagogy or to upgrade their educational competences over their professional lifespan (IMHE, September 2012). This, we believe is a big loophole, given that many institutions, including major research universities, are challenged by the increasing diversity of students that has resulted from the increasing share of young people enrolling in higher education along with more mature students. At the same time, institutions are coming under greater public pressure to demonstrate that they are preparing their graduates for the labour market and to show what value students will get in return for the cost of their education whether paid for by the student or the taxpayer. So, shouldn't we pay special attention on who teaches what, when and where?

\section{Conclusions}

There are three major reasons that influence academicians to teach outside their areas of expertise. These include the personal, philosophical and institutional. However, although both empirical evidence and literature have found no harm in one attempting something new, there are both positive and negative implications. The issue in question is rarely discussed because of the risks associated with it. The first possibility about those who teach outside their expertise is that individuals are either unaware of their actual expertise or are ignorant; and the second one is that of being dishonest. This is a tricky situation, especially when heads of institutions are not willing to openly discuss the matter, given that even students (who are the major key stakeholders) are a captive audience, which actually frightens them off. 
Yet, some individuals have found teaching outside their expertise quite seductive, because most individuals find this to be the best opportunity to show off high levels of knowledge or competence. On the other hand, it is a crucial step in developing motivation to learn in those with enthusiasm and zeal. The personalities who have excelled in teaching outside their expertise more often have been driven by enthusiasm to show something that is beyond the students' reach, although not so far beyond it that they will despair. Interestingly, individuals who have succeeded have made the interaction extremely exciting and have made the learning environment memorable. This move, from 'knowing that you don't know' to 'knowing that you know' is what most learning and hence teaching is all about and what creates a sense of achievement.

Another possibility is that the person who knows that she/he knows may not know how she or he knows; or cannot express it. It should be noted that there are individuals who are afraid to express their expertise (even if they had it), for fear of inadequate exposition that might jeopardize their fragile knowledge, and if done, it might become hardened. Many even feel obliged to live up to their exposition and limit that insight and creativity which goes beyond words which is quite unfortunate. Clearly therefore, we have to get people to realize what they do not know, if necessary. But fascinating though it is, the inarticulate expertise of not knowing that one knows is a dead end from the learning and teaching point of view. Hence, the only open position, with potential for development, is that of knowing what one knows. Much of what we know, we know that we know. Less obvious to most people, however, is that there are things we do not know that we do not know. Consequently, it can be very disastrous to proceed and deliver where we do not have expertise and yet we do not know that we do not know. Hence, problem acknowledgement is critical in this aspect.

Curiosity or deception aside, there have been drivers that have forced individuals into teaching what they never studied. Visibly, market-driven programmes and performance-based pay have exacerbated this practice. Although scholars acknowledge that teaching is not a matter of what one learnt in school or not to a large extent, it can lead to undesirable effects. Individuals have been found to teach effectively in areas they do not have expertise. This has been attributed to; intellectual curiosity, self-actualization, and a need for achievement.

To a large extent, whether teaching out of curiosity or deception, the practice has been driven by, structural factors, institutional-related factors and lack of differentiation within institutions. 


\section{$5 \quad$ Recommendations}

Instead of higher education managers continuing to condemn those who teach outside their areas of expertise, they should instead encourage academicians to develop a critical stance in reading, thinking and methodological approach to exhibit more knowledge than the students. If this practice is to be curbed, institutions should address unrealistic demands of work-load requirements. If individuals teaching out of curiosity have to continue, they should be encouraged to go an extra mile in order to add value to their students' learning. Institutions should endeavour to train new teaching staff in pedagogical and andragogical methods to perfect their work. However, this attempt requires commitment, ethical behaviour, and continuous practice. The best approach is to look closely at teaching as facilitation and as coaching to better understand these two roles and why they are vital in teaching for understanding and transferring of knowledge, and how both content experts and novices can muddle the game if not well prepared. Those who teach outside their area of expertise need to search for more information, practice critical reading and thinking, determination, zeal and motivation. This seems to be what matters to turn one into an expert.

The training should be thought about seriously; and whether in small seminars or large lectures, students ought to be guided to actively process information and test their understanding rather than simply listen and take notes. Therefore, since facilitative teaching rests on the common belief that learners can develop understanding (even in large lecture courses) they should be asked to continually question and rethink their answers in the light of feedback in order to understand. Hence, content expertise, methodological emancipation, adequate preparations, continuous monitoring and evaluation, a positive attitude and academic grounding, combined together, will lead to superior facilitation.

Research should be prioritized or at least be balanced with the teaching so that this teaching or workload phenomenon does not deplete the essence of the mandates of higher education institutions.

\section{References}

Bain, K. (2004). What the Best College Teachers Do. Cambridge, Mass: Harvard University Press.

Barifaijo, K.M., Karyeija, K.G., Namara, R., Kyohairwe, S., \& Ssentamu, N.P. (2015). Workload Policy and its Intricacies in the Academic Profession: Implications for Higher Education. International Journal of Business, Social Sciences and Education. 1 (4), 270-301. 
Brookfield, S. D. (1995). Becoming a critically reflective teacher. San Francisco: Jossey-Bass.

Brookfield, S. D. (2005). Discussion as a way of Teaching: Tools and Techniques for Democratic Classrooms. Francisco, Calif.: Jossey-Bass.

Cranton, P. (2002). Teaching for transformation. 'New Directions for Adult and Continuing Education,' (93) 63-71. In Special Issue: Contemporary viewpoints on teaching adults effectively.

Demeroutiet, E., Bakker, A. B., Nachreiner, F., \& Schaufeli, W. B. (2001). The job demands-resources model of burnout. Journal of Applied Psychology, 86(3), 499-512. doi: http://dx.doi.org/10.1037/0021-9010.86.3.499.

Donovan, M. S., Bransford, J. D., \& Pelegrino, J. W. (Eds.). (1999). How People Learn: Bridging Research and Practice. Washington DC: National Academy Press.

Ganster, D.C., \& Rosen, C.C. (2013). Why Entrepreneurs Often Experience Low, Not High, Levels of Stress: The Joint Effects of Selection and Psychological Capital. Journal of Management, 42: 742-768.

Gappa, J. M., Austin, A. E., \& Trice, A. G. (2007). Rethinking Faculty Work: Higher Education's Strategic Imperative. San Francisco: John Wiley and Sons.

Gross-Davis, B. (2009).Tools for Teaching, $2^{\text {nd }}$ edition. San Francisco, Calif.: Jossey-Bass.

Hsien-Hui, T., Emily, H. (2013). The advantages and disadvantages of multidisciplinary collaboration in design education. National Taiwan University of Science and Technology

Huston, T. (2009). Teaching What You Don't Know. Harvard University Press, Cambridge, Massachusetts and London.

IMHE (September, 2012). Fostering Quality Teaching in Higher Education: Policies and

Practices. http://www.oecd.org/edu/imhe/QT\%20policies\%20and\%20practices.pdfacce ssed on $19^{\text {th }}$ February 2016

Kasozi, A. B. K. (2006). The state of higher education and training in Uganda 2006. Kampala: National Council for Higher Education.

Kothari, C.R. (2004). Research Methodology. Methods and Techniques. Second Revised Edition. New Delhi: New Age International Publishers.

Laird, D. (1985). Approaches to training and development. Addison-Wesley: Reading Mass.

Lang, J. M. (2008). On-Course: A Week-by-Week Guide to your First Semester of College Teaching. Cambridge, Mass.: Harvard University Press.

McKeachie, W., \& Marilla, S. (2006). Teaching Tips: Strategies, Research, and Theory for College and University Teachers, $12^{\text {th }}$ Ed. Boston: Houghton Mifflin. 
Mulryan-Kyne, C. (2010). Teaching Large Classes at College and University: Challenges and Opportunities. Teaching in Higher Education, 15, 175-185.

Nilson, L. (2007). Teaching at Its Best: A Research-Based Resource for College Instructors, $2^{\text {nd }}$ ed. San Francisco, Calif.: Jossey-Bass.

Orrell, J. (2011). Good Practice Report: Work-integrated Learning, Australian Learning and Teaching Council. http://www.olt.gov.au/resource-workintegrated-learning. Accessed 26 April, 2015.

Race, P. (2007). The Lecturer's Toolkit: A Resource for Developing Assessment, Learning and Teaching, $3^{\text {rd }}$ edition, London: Routledge Press.

Rogers, Carl. (1980). A Way of Being. Boston: Houghton Mifflin.

Smith, K.T., \& Mistry, B. (2009). Predictive Operational Performance (PrOPer) Model. Contemporary Ergonomics 2009, Proceedings of the International Conference on Contemporary Ergonomics.

Svinicki, M. D. (1999). New directions in learning and motivations. New Directions for Teaching and Learning, 80, 5-27. 